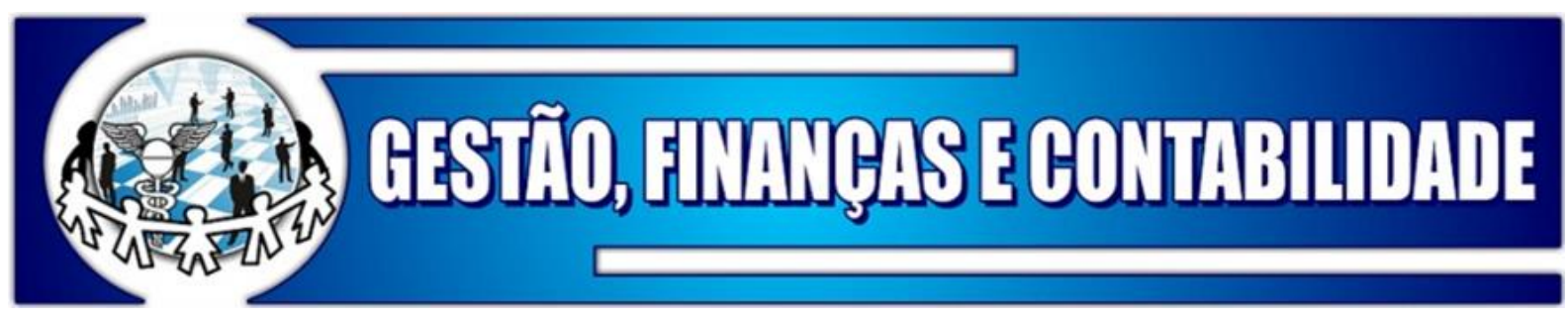

\title{
SUSTENTABILIDADE EM MICRO E PEQUENAS EMPRESAS: A VISÃO DO CONTADOR
}

\author{
SUSTAINABILITY IN MICRO AND SMALL BUSINESSES: \\ THE ACCOUNTANT'S VIEW
}

\section{SOSTENIBILIDAD EN MICRO Y PEQUEÑAS EMPRESAS: LA VISIÓN DEL CONTADOR}

\author{
Luana Cristina dos Santos Oliveira \\ https://orcid.org/0000-0003-0024-2758 \\ Graduada em Ciências Contábeis pela Universidade Federal de Minas Gerais (UFMG) \\ E-mail: luanacsoliveira@gmail.com
}

\begin{abstract}
Rafaella Duarte Miranda
https://orcid.org/0000-0003-0537-7408
\end{abstract}

Mestra em Controladoria e Contabilidade pela Universidade Federal de M. Gerais (UFMG)

E-mail: rafaellamiranda.rm@gmail.com

Renata Turola Takamatsu

https://orcid.org/0000-0002-0422-9895

Professora do Programa de Pós-graduação em Controladoria e Contabilidade da Universidade

Federal de Minas Gerais (PPGC/UFMG)

Doutora em Controladoria e Contabilidade pela Universidade de São Paulo (USP)

E-mail: rettakamatsu@gmail.com

\begin{abstract}
RESUMO
A mortalidade das Micro e Pequenas Empresas (MPEs) tem sido alvo de estudos no meio acadêmico, contudo, pouco se pode afirmar sobre a relação existente entre a contabilidade, a formação acadêmica do profissional, a consultoria e a sobrevivência das MPEs. Desta forma, o presente estudo objetivou avaliar a percepção dos contadores acerca da sustentabilidade em MPE e como a consultoria contábil poderia auxiliar estas empresas na manutenção de suas atividades. Foram realizadas 12 entrevistas semiestruturadas com profissionais representantes de escritórios contábeis e a análise dos dados captados nas entrevistas se deu por meio de técnicas de análise de conteúdo. Os resultados apontaram como as 6 principais causas dos altos índices de mortalidade enfrentados pelas MPEs, na visão dos entrevistados: burocracias relativas ao mercado; dificuldades financeiras enfrentadas pelas empresas; alta carga tributária; incapacidade de gestão do empreendedor; situação econômica do país; e mudança de ramo e/ou porte da entidade. Ainda, observou-se que estes índices podem ser amenizados por meio da prestação do serviço de consultoria contábil, principalmente no que tange ao planejamento prévio, antes da abertura da empresa.
\end{abstract}

Palavras-Chave: Consultoria Contábil; Micro e Pequenas Empresas; Mortalidade das MPEs. 


\begin{abstract}
The mortality of Micro and Small Enterprises (MPEs) has been the subject of studies in the academic environment, however, little can be said about the relation between accounting, the academic training of professionals, consultancy and the survival of MPEs. In this way, the present study aimed to evaluate the accountants' perception about sustainability in MPE and how the accounting consultancy could assist these companies in maintaining their activities. 12 semi-structured interviews were carried out with professionals representing accounting firms, and the analysis of the data captured in the interviews was carried out using content analysis techniques. The results pointed out as the 6 main causes of the high mortality rates faced by MPEs, from the interviewees' point of view: bureaucracies related to the market; financial difficulties faced by companies; high tax burden; entrepreneur's inability to manage; economic situation in the country; and change of branch and / or size of the entity. Still, it was observed that these indexes can be mitigated through the provision of the accounting consultancy service, especially with regard to prior planning, before the opening of the company.
\end{abstract}

Keywords: Accounting Consulting; Micro and Small Companies; Mortality of MSEs.

\title{
RESUMEN
}

La mortalidad de las micro y pequeñas empresas (MPEs) ha sido objeto de estudios en el entorno académico, sin embargo, poco se puede decir sobre la relación entre la contabilidad, la formación académica de los profesionales, la consultoría y la supervivencia de las MPE. Desta forma, o presente estudo objetivou avaliar a percepção dos contadores acerca da sustentabilidade em MPE y como una consultoría contábil poderia auxiliares estas empresas na manutenção de sus actividades. Se realizaron 12 entrevistas semiestructuradas con profesionales que representan a empresas de contabilidad, y el análisis de los datos capturados en las entrevistas se realizó a través de técnicas de análisis de contenido. Los resultados señalaron como las 06 causas principales de las altas tasas de mortalidad a las que se enfrentan las MPEs en opinión de los entrevistados: burocracias relacionadas con el mercado; dificultades financieras que enfrentan las empresas; alta carga fiscal; incapacidad para gestionar al emprendedor; situación económica del país; cambio de sucursal y tamaño de la entidad. Aún así, se observó que estos índices pueden mitigarse mediante la prestación del servicio de consultoría contable, principalmente con respecto a la planificación previa, antes de la apertura de la empresa.

Palabras clave: Consultoría contable; Micro y Pequeñas Empresas; Mortalidad de las MPE.

\section{INTRODUÇÃO}

Com representação de $90 \%$ das empresas, $60 \%$ da carga tributária, geração de emprego e renda, as Micro e Pequenas Empresas (MPEs) tornam-se importantes no cenário econômico brasileiro, à medida que se referem ao maior número de empresas no país (PEREIRA, 2017). Estas entidades servem de amortecedor do desemprego, pois representam uma alternativa de ocupação para a população, seja ela em condições de desenvolver o próprio negócio, ou a parcela de trabalho excedente, que, geralmente, com pouca qualificação, não encontra emprego em empresas de grande porte.

Mesmo com a significativa relevância econômica e social, as MPEs ainda necessitam de atenção relativa à sua taxa de sobrevivência. O percentual médio de MPEs que sobreviveram até dois anos foi de 54,2\% para empresas criadas em 2008 e de 76,6\% para empresas criadas em 2012. Destaca-se que as empresas criadas em 2012 foram beneficiadas por alguns aspectos positivos, como: a expansão do Microempreendedor Individual (MEI), a evolução do PIB, a tendência de queda da taxa de juros, a expansão acumulada de $25 \%$ acima da inflação do rendimento médio real dos trabalhadores, a também expansão acumulada do salário mínimo 
real em 30\% acima da inflação e a queda da taxa de desemprego, nas principais regiões metropolitanas, em quase 50\% (SEBRAE, 2016).

No estudo realizado pelo SEBRAE, em 2016, verificou-se que a mortalidade de um negócio é resultado de uma combinação de fatores contribuintes, sendo eles: situação antes da abertura (tipo de ocupação do empresário, experiência no ramo e motivação para abrir um negócio), planejamento do negócio, gestão do negócio e capacitação dos donos em gestão empresarial (SEBRAE, 2016).

No entanto, de acordo com Williams e O'Donovan (2015) a pesquisa acadêmica internacional ainda está amplamente focada nas empresas de grande porte, sendo os estudos na área de pequenas e médias empresas fragmentados, menos desenvolvidos e/ou limitados. Embora as práticas e estruturas de negócios sejam muito diferentes em empresas de menor porte, coletivamente, as pequenas empresas desempenham um papel fundamental em qualquer economia em desenvolvimento.

As MPEs apresentam problemas específicos, principalmente na área de gestão. Segundo Neitzke e Oliveira (2014, p. 4), "a gestão de uma empresa é o principal fator para seu sucesso ou insucesso". Para auxiliar as MPEs, nestes problemas específicos relativos à gestão, o contador se torna aliado, à medida que é um consultor potencial e pode contribuir de forma eficaz para a sobrevivência das empresas (CARNEIRO; DALL'AGNOL, 2005, 2004).

Nesse sentido, Oosthuizen (2018) - na África do Sul - e Ogane (2021) - no Japão demonstraram os benefícios dos serviços de consultoria por parte do contador, tanto em se tratando de benefícios em termos de gestão quanto na agregação de valor e desempenhos futuros das empresas. Dado o importante papel que empresas de pequeno porte desempenham na economia, Yassen (2018) destaca que é fundamental identificar as formas nas quais este setor pode ser apoiado e, especificamente, compreender o papel atual e futuro da profissão contábil no apoio a esse rol de empresas. Ainda assim, apesar de ativos, pouco se sabe sobre o papel que o contador desempenha e quais são suas percepções e contribuições nesse ambiente.

Diante desse contexto, o presente estudo faz parte do rol de pesquisas que analisa diferentes maneiras pelas quais práticas gerenciais auxiliam na sustentabilidade de micro e pequenas empresas, sob a perspectiva de um profissional externo, especificamente, o contador. Portanto, o objetivo do presente trabalho é avaliar a percepção dos contadores acerca da sustentabilidade em MPE e como a consultoria contábil poderia auxiliar estas empresas na manutenção de suas atividades.

Segundo Lima e Mioto (2007), a constatação do desenvolvimento econômico como principal fator para a produção de conhecimento já se torna o motivo pelo qual pesquisas devem ser produzidas e encaminhadas. Abordando as características inerentes à consultoria contábil para as MPEs, este trabalho tem o intuito de auxiliar a sobrevivência e continuidade das Micro e Pequenas Empresas. Afinal, O contador, por estar atrelado diariamente às MPEs, prestandolhes serviços contábeis, fiscais, de departamento pessoal, entre outros, é um consultor em potencial, vista sua proximidade com os empresários/empreendedores e com as atividades das empresas. Assim, este profissional pode contribuir efetivamente para a sobrevivência das MPEs e para a melhora de seu desempenho.

\section{REVISÃO DA LITERATURA}

\subsection{MICRO E PEQUENAS EMPRESAS E CONSULTORIA CONTÁBIL}

Para Lemes e Pisa (2010), a definição de Micro e Pequenas Empresas (MPEs) não está atrelada apenas a um critério. Diferenças ocorrem tanto no Brasil como em qualquer outro país, seja de região para região dentro do mesmo país, ou até mesmo entre órgãos não governamentais ou governamentais, e entre instituições de apoio ou particulares. 
No Brasil, há uma multiplicidade de definições para as MPEs e estabelecer qual classificação será utilizada no estudo é relevante, dada a dificuldade de harmonização entre os conceitos. Assim, a caracterização de MPEs utilizada será a apresentada pelo SEBRAE-SC. Esta classificação se dá pela Receita Bruta Anual (RBA) adotada na Lei Complementar $\mathrm{n}^{\circ} 123$, de 14 de dezembro de 2006, e pelo número de empregados utilizado pelo Instituto Brasileiro de Geografia e Estatística (IBGE) para fins bancários, exportação, tecnologia, entre outros. Esta caracterização pode ser visualizada na Tabela 1.

Tabela 1: Classificação das MPEs de acordo com a RBA e o número de empregados - SEBRAE-SC.

\begin{tabular}{c|c|c|c|c}
\hline \multirow{2}{*}{ Porte } & \multicolumn{2}{|c|}{ Indústria } & \multicolumn{2}{c}{ Comércio e Serviços } \\
\cline { 2 - 5 } & $\mathbf{N}^{\mathbf{0}}$ Empregados & RBA $(\mathbf{R} \mathbf{)}$ & $\mathbf{N}^{\mathbf{0}}$ Empregados & RBA (R\$) \\
\cline { 2 - 5 } & De - até & De - até & De - até & De - até \\
\hline Microempresa & $0-19$ & $1-360.000$ & $0-9$ & $1-360.000$ \\
\hline Pequena Empresa & $20-99$ & $360.001-3.600 .000$ & $10-49$ & $360.001-3.600 .000$ \\
\hline
\end{tabular}

Fonte: Dados obtidos no portal SEBRAE-SC.

No Brasil, o montante de MPEs têm crescimento acentuado desde 2009, com estimativa de 4.143.505 microempresas (MEs) e 1.130.679 empresas de pequeno porte (EPP) em 31 de dezembro de 2017 (SEBRAE, 2017b). Notadamente, vê-se o impacto que as MPEs exercem na economia brasileira, portanto, sua continuidade deve ser priorizada e incentivada. Para a sobrevivência e manutenção das MPEs, diversos fatores devem ser observados, entre eles está o planejamento adequado do negócio antes de sua abertura, a qualidade da gestão do negócio e a capacitação dos donos em gestão empresarial (SEBRAE, 2016). Nesse contexto, o contador ganha papel relevante como uma das principais fontes de informações e auxílio às MPEs. Afinal, este profissional encontra-se junto à empresa desde antes de seu nascimento até o seu possível fechamento. Com isso, ressalta-se o contador atuando como potencial consultor destas entidades, com a finalidade de auxiliar na sobrevivência das MPEs.

O Conselho Regional de Contabilidade do estado de São Paulo - CRCSP (2011), ao elaborar o Manual de Técnicas e Práticas de Consultoria Contábil junto às Pequenas e Médias Empresas, descreve a consultoria contábil como um método de auxílio prático e aconselhamento, o qual pode ser implementado nas pequenas e médias empresas brasileiras, com sucesso, por meio de seus próprios funcionários, devidamente credenciados ou homologados e treinados. Ou seja, o contabilista possui condições técnicas para aconselhamento e auxílio de forma prática à empresa, objetivando que a mesma obtenha um bom desempenho no seu negócio, atendendo aos princípios e fundamentos legais.

A atividade de consultoria é caracterizada por meio da prestação de serviços sob a forma de opiniões, aconselhamentos, pareceres etc. Não obstante, o consultor contábil poderá contribuir para a otimização do desempenho econômico-financeiro da empresa, através do aperfeiçoamento contínuo e da eliminação de desperdícios ocorridos nos processos administrativos e de produção, bem como em um aumento no nível de melhoria de serviços prestados aos clientes e a minimização do custo logístico total (Kubr, 1989). Berti (2012) ressalta que é necessário um alto grau de confiança entre o consultor e o cliente para o desenvolvimento de um bom trabalho de consultoria, evitando-se o truncamento de informações. É preciso que o consultor conheça a empresa para, assim, desenvolver o trabalho de consultoria.

O consultor contábil, do ponto de vista ético, deverá oferecer ao cliente orientações e opiniões latentes para o alcance dos seus propósitos, ao mesmo tempo que deve denunciar todos os desvios encontrados referentes a tal propósito (SÁ, 2008). É relevante também que o consultor entenda que não é apenas um conselheiro, ou seja, o seu trabalho não deve se ater apenas a recomendações e estudos, mas, sim, auxiliar na implementação do plano aprovado (BERTI, 2012).

Ademais, a cultura contábil do cliente torna-se fundamentalmente crítica para o sucesso da consultoria contábil à medida que é relevante para a implementação de toda forma e tipo de 
mudança. Se a cultura contábil for de natureza tributária, majoritariamente ou exclusivamente, deverá haver um alinhamento preliminar de entendimento entre o consultor e o cliente. Nesse caso, a contabilidade é vista somente como uma obrigação legal de contabilização de eventos e transações, com o único fim de atender às exigências tributárias e fiscais (CRCSP, 2011).

\subsection{PESQUISAS ANTERIORES}

As Micro e Pequenas Empresas têm sido alvo de estudos acerca de casos de sucesso e insucesso, vista a prematuridade a qual seu ciclo de vida tem sido interrompido. Assim, foi elaborado o Quadro 1, com o objetivo de demonstrar, sinteticamente, os principais resultados encontrados inerentes às causas que levam à mortalidade das MPEs.

Quadro 1 - Estudos Acerca das Causas de Mortalidade das MPEs.

\begin{tabular}{|c|c|c|c|}
\hline $\begin{array}{c}\text { Autor (es) } \\
\text { (Ano) }\end{array}$ & Objetivos & Objetivos & Principais Resultados \\
\hline $\begin{array}{l}\text { Carneiro e } \\
\text { Dall'Agnol } \\
(2005,2004)\end{array}$ & $\begin{array}{l}\text { Demonstrar que é } \\
\text { possível reduzir a alta } \\
\text { taxa de mortalidade } \\
\text { das Micro e Pequenas } \\
\text { Empresas no Brasil, } \\
\text { na ordem de quase } \\
50 \% \text { nos dois } \\
\text { primeiros anos, por } \\
\text { meio da consultoria } \\
\text { especializada em } \\
\text { gestão, realizada por } \\
\text { profissionais da } \\
\text { contabilidade. }\end{array}$ & $\begin{array}{l}\text { O estudo, de cunho } \\
\text { teórico, apresentou como } \\
\text { pilar uma relação entre a } \\
\text { Teoria Geral dos Sistemas } \\
\text { e o Sistema de Gestão das } \\
\text { Micro e Pequenas } \\
\text { Empresas (MPE). }\end{array}$ & $\begin{array}{l}\text { - No cotidiano empresarial, } \\
\text { conhecimento é especialmente } \\
\text { importante para sucesso, uma vez que } \\
\text { não há margem para falhas, diante da } \\
\text { grande competitividade existente. } \\
\text { - Aprendizagem encontra-se } \\
\text { justificada, sobretudo, na essência da } \\
\text { contribuição que o profissional da } \\
\text { contabilidade pode oferecer para o } \\
\text { setor econômico, ao auxiliar na } \\
\text { contenção da mortalidade das } \\
\text { empresas. }\end{array}$ \\
\hline $\begin{array}{l}\text { Ortigara et } \\
\text { al. }(2006)\end{array}$ & $\begin{array}{l}\text { Identificar as causas } \\
\text { de mortalidade e/ou } \\
\text { sucesso das Micro e } \\
\text { Pequenas Empresas } \\
\text { (MPEs) do Estado de } \\
\text { Santa Catarina. }\end{array}$ & 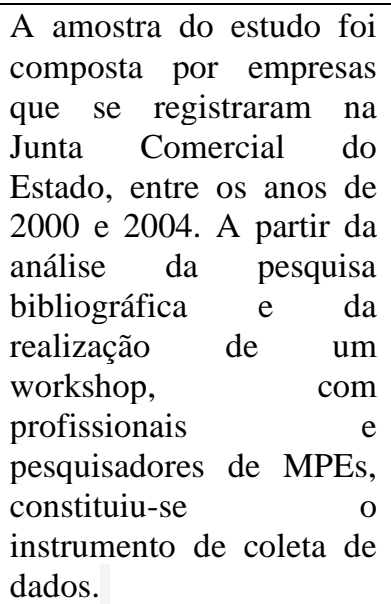 & $\begin{array}{l}\text { - Procura de assessoria pelos } \\
\text { empresários no início do negócio. } \\
\text { - Sintomas de mortalidade mais } \\
\text { relevantes: carga tributária, falta de } \\
\text { capital de giro e inadimplência dos } \\
\text { clientes. } \\
\text { - Fatores de sucesso mais relevantes: } \\
\text { bom conhecimento do mercado, boa } \\
\text { estratégia de vendas, empresário com } \\
\text { persistência e perseverança e } \\
\text { aproveitamento das oportunidades do } \\
\text { negócio. }\end{array}$ \\
\hline $\begin{array}{l}\text { Bonacim, } \\
\text { Cunha e } \\
\text { Corrêa } \\
(2009)\end{array}$ & $\begin{array}{l}\text { Apontar os principais } \\
\text { fatores propulsores da } \\
\text { mortalidade de MPEs } \\
\text { do Município de } \\
\text { Ituverava, em São } \\
\text { Paulo. }\end{array}$ & $\begin{array}{l}\text { Os autores entrevistaram } \\
\text { nove empresários de } \\
\text { negócios não bem- } \\
\text { sucedidos } \\
\text { posteriormente, } \\
\text { realizaram duas sessões } \\
\text { de grupos focais. }\end{array}$ & $\begin{array}{l}\text { - Principais causas de mortalidade: } \\
\text { falta de planejamento prévio, } \\
\text { escassez de linhas de crédito, baixa } \\
\text { demanda por seus produtos e } \\
\text { serviços, elevada carga tributária. } \\
\text { - Houve um consenso entre os } \\
\text { empreendedores a respeito de que, } \\
\text { antes da abertura de qualquer negócio, } \\
\text { eles deveriam procurar ajuda } \\
\text { profissional para conhecer mais sobre o } \\
\text { mercado e os riscos enfrentados, } \\
\text { proceder à análise da concorrência e } \\
\text { estimar com mais precisão o capital } \\
\text { necessário para a abertura do negócio e } \\
\text { para giro. }\end{array}$ \\
\hline $\begin{array}{l}\text { Ferreira et } \\
\text { al. }(2012)\end{array}$ & $\begin{array}{l}\text { Apontar quais são os } \\
\text { principais } \\
\text { associados } \\
\text { com atores } \\
\end{array}$ & $\begin{array}{l}\text { Os autores realizaram uma } \\
\text { pesquisa com os gestores } \\
\text { de micro e pequenas }\end{array}$ & $\begin{array}{l}\text { Os principais fatores associados com a } \\
\text { mortalidade precoce das micro e } \\
\text { pequenas empresas são: }\end{array}$ \\
\hline
\end{tabular}


Oliveira, Miranda e Takamatsu (2021)

Sustentabilidade em Micro e Pequenas Empresas: A Visão do Contador

\begin{tabular}{|c|c|c|c|}
\hline & $\begin{array}{l}\text { mortalidade das micro } \\
\text { e pequenas empresas. }\end{array}$ & $\begin{array}{l}\text { empresas, situadas na } \\
\text { cidade de São Paulo, que } \\
\text { encerraram suas } \\
\text { atividades. Entrevistas } \\
\text { foram aplicadas como } \\
\text { instrumentos de coleta de } \\
\text { dados e aplicou-se a } \\
\text { técnica de análise fatorial. }\end{array}$ & $\begin{array}{l}\text { - Ausência de planejamento ou plano de } \\
\text { negócios. } \\
\text { - Falta de inovação, design ou } \\
\text { desempenho dos produtos e serviços. } \\
\text { - Dificuldade em conquistar e manter } \\
\text { clientes. } \\
\text { - Nível elevado de concorrência; } \\
\text { - Baixo nível de escolaridade do } \\
\text { empreendedor. } \\
\text { - Competência gerencial diminuta. }\end{array}$ \\
\hline $\begin{array}{l}\text { Albuquerque } \\
(2012)\end{array}$ & $\begin{array}{l}\text { Apresentar uma visão } \\
\text { geral sobre fatores de } \\
\text { mortalidade de } \\
\text { pequenas empresas e } \\
\text { identificar os } \\
\text { principais fatores } \\
\text { citados na literatura } \\
\text { especializada. }\end{array}$ & $\begin{array}{l}\text { A pesquisa utilizou-se de } \\
\text { uma abordagem } \\
\text { qualitativa, sendo os } \\
\text { dados coletados por meio } \\
\text { de entrevistas e os } \\
\text { documentos analisados } \\
\text { por meio da técnica de } \\
\text { análise de conteúdo. }\end{array}$ & $\begin{array}{l}\text { - A principal conclusão do artigo é que } \\
\text { nenhum fator, isoladamente, pode } \\
\text { explicar a mortalidade precoce das } \\
\text { pequenas empresas, pois são } \\
\text { interdependentes e contribuem para o } \\
\text { sucesso ou insucesso empresarial. } \\
\text { - Os cinco fatores mais discutidos na } \\
\text { literatura estão relacionados à empresa } \\
\text { e ao ambiente: o planejamento formal, } \\
\text { os fatores relacionados às áreas } \\
\text { funcionais, as condições econômicas, a } \\
\text { concorrência e o mercado consumidor. }\end{array}$ \\
\hline $\begin{array}{l}\text { Vannucci } \\
\text { (2017) }\end{array}$ & $\begin{array}{l}\text { Investigar os fatores } \\
\text { que afetam a } \\
\text { mortalidade } \\
\text { Micro e Pequenas } \\
\text { Empresas, na } \\
\text { percepção de alguns } \\
\text { empresários da cidade } \\
\text { de Uberlândia. }\end{array}$ & $\begin{array}{l}\text { A coleta dos dados foi } \\
\text { realizada por meio da } \\
\text { aplicação de um } \\
\text { questionário. A amostra } \\
\text { do estudo foi composta } \\
\text { por } 25 \text { empresários, } \\
\text { situados na cidade de } \\
\text { Uberlândia. }\end{array}$ & $\begin{array}{l}\text { Para os empresários a determinante de } \\
\text { maior relevância está relacionada à } \\
\text { gestão empresarial exercida na empresa e } \\
\text { à forma como são conduzidas as } \\
\text { ferramentas de gestão nas organizações. }\end{array}$ \\
\hline
\end{tabular}

Fonte: Elaborado pelos autores.

Em diferentes períodos, o planejamento foi um dos principais fatores mais citados pelos autores quando se remete à causa da mortalidade das MPEs (BONACIM, CUNHA E CORRÊA, 2009; FERREIRA ET AL., 2012; ALBUQUERQUE E FILHO, 2012; VANNUCCI, 2017). Os resultados retratados no Quadro 1 corroboram com a necessidade e importância do contador junto às MPEs, à medida que a consultoria contábil permite o direcionamento destas entidades para um planejamento de negócio efetivo, que proporcionará uma melhor visão ao proprietário e auxiliará tanto no início quanto na manutenção das suas atividades.

No âmbito internacional, encontram-se pesquisas sobre o papel do contador nas empresas de pequeno porte, como pode ser observado abaixo:

Quadro 2 - Estudos Acerca das Causas de Mortalidade das MPEs.

\begin{tabular}{|c|c|c|c|}
\hline Autor (es) & Objetivos & Método & Principais Resultados \\
\hline $\begin{array}{l}\text { Yassen } \\
(2018)\end{array}$ & $\begin{array}{l}\text { O autor teve como } \\
\text { objetivo avaliar como } \\
\text { contadores profissionais e } \\
\text { proprietários de PMEs, na } \\
\text { África do Sul, vivenciam } \\
\text { o papel atual do contador. } \\
\text { Em adição, o pesquisador } \\
\text { também quis traçar as } \\
\text { expectativas sobre o } \\
\text { futuro papel dos } \\
\text { contadores profissionais } \\
\text { no apoio às PME. }\end{array}$ & 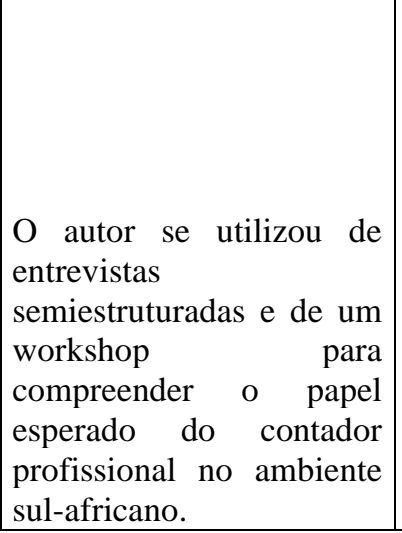 & $\begin{array}{l}\text { O estudo concluiu que a função atual do } \\
\text { contador é significativamente } \\
\text { influenciada por estereótipos, ética e } \\
\text { experiências. } \\
\text { O papel atual dos contadores } \\
\text { profissionais no ambiente das PME foi } \\
\text { segregado entre papéis tradicionais, não } \\
\text { tradicionais e emergentes. Em adição, os } \\
\text { participantes do workshop realizado } \\
\text { foram capazes de criar uma imagem do } \\
\text { que seria o papel futuro de sucesso para } \\
\text { o contador profissional em PMEs sul- } \\
\text { africanas. }\end{array}$ \\
\hline
\end{tabular}


Oliveira, Miranda e Takamatsu (2021)

Sustentabilidade em Micro e Pequenas Empresas: A Visão do Contador

\begin{tabular}{|c|c|c|c|}
\hline & $\begin{array}{l}\text { O autor buscou } \\
\text { desenvolver um modelo } \\
\text { preditivo para prever } \\
\text { quais serviços os clientes } \\
\text { precisariam contratar } \\
\text { junto aos seus contadores, } \\
\text { além das expectativas dos } \\
\text { clientes de pequenas } \\
\text { empresas quanto à } \\
\text { qualidade do serviço. }\end{array}$ & $\begin{array}{lr}\text { O autor analisou as } \\
\text { percepções de } 422 \\
\text { proprietários de pequenas } \\
\text { empresas, } \\
\text { modelagem de equações } \\
\text { estruturais. }\end{array}$ & $\begin{array}{l}\text { O estudo apontou que empresas } \\
\text { consideram os serviços relacionados às } \\
\text { demonstrações financeiras padronizadas } \\
\text { como sendo de benefício limitado. } \\
\text { Constatou-se que as PMEs que } \\
\text { frequentemente contratam outros } \\
\text { serviços de contabilidade, relacionados à } \\
\text { parte tributária e consultoria geral, obtêm } \\
\text { maiores níveis de compliance e de } \\
\text { benefício gerencial, demonstrando a } \\
\text { importância de que esses serviços sejam } \\
\text { procurados com mais frequência. }\end{array}$ \\
\hline $\begin{array}{l}\text { Blackburn, } \\
\text { Carey e } \\
\text { Tanewski } \\
(2018)\end{array}$ & $\begin{array}{l}\text { O objetivo dos autores foi } \\
\text { avaliar o papel dos } \\
\text { relacionamentos e da } \\
\text { confiança na contratação } \\
\text { dos serviços de } \\
\text { consultoria empresarial } \\
\text { oferecidos por contadores } \\
\text { aos proprietários de } \\
\text { pequenas empresas. }\end{array}$ & $\begin{array}{l}\text { O estudo usa uma } \\
\text { abordagem de entrevista } \\
\text { semiestruturada com } 20 \\
\text { proprietários e contadores } \\
\text { de pequenas e médias } \\
\text { empresas (PME), em } \\
\text { Londres e Melbourne. }\end{array}$ & $\begin{array}{l}\text { Os resultados da entrevista apoiam a } \\
\text { proposição de que os relacionamentos } \\
\text { prévios e a confiança, em vez de serem } \\
\text { antecedentes da demanda por } \\
\text { aconselhamento, são condições } \\
\text { necessárias para permitir a demanda } \\
\text { latente. As PMEs com maior propensão } \\
\text { à confiança são mais abertas a contratar } \\
\text { serviços de consultoria de negócios. }\end{array}$ \\
\hline & $\begin{array}{l}\text { Os autores avaliaram os } \\
\text { efeitos do aconselhamento } \\
\text { externo sobre o } \\
\text { desempenho e a } \\
\text { arrecadação de fundos, } \\
\text { além de distinguir as } \\
\text { fontes de aconselhamento. }\end{array}$ & $\begin{array}{l}\text { O autor realizou um } \\
\text { survey, por meio de } \\
\text { questionários aplicados } \\
\text { em } 3.011 \text { novas empresas } \\
\text { do Japão. }\end{array}$ & $\begin{array}{l}\text { Dentre os resultados encontrados, foi } \\
\text { detectado que os conselhos dos } \\
\text { contadores contribuem para melhorar o } \\
\text { desempenho de empresas em estágio } \\
\text { inicial, além de agregar valor para } \\
\text { startups. }\end{array}$ \\
\hline
\end{tabular}

Fonte: Elaborado pelos autores.

Yassen (2018) destaca o amplo rol de atuação dos contadores profissionais no ambiente das PME, que abrangem desde papéis tidos como tradicionais, até os papeis não tradicionais e emergentes. O papel do contador na consultoria de empresas de pequeno porte é o foco do presente trabalho, em que se é possível encontrar, na literatura, evidências empíricas que demonstram que as empresas que tiveram consultoria contábil, de fato, tiveram mais sucesso na gestão e na perpetuidade dos negócios. Dentre esses estudos, Oosthuizen (2018) constatou que as PMEs que frequentemente contratam serviços relacionados à consultoria geral (além de serviços fiscais), obtém maiores benefícios em termos de gestão. Ogane (2021) reforça a perspectiva acerca da relevância dos serviços de consultoria por parte dos contadores, demonstrando empiricamente que os conselhos dos contadores agregam valor e contribuem para melhorar o desempenho de empresas em estágio inicial.

Blackburn, Carey e Tanewski (2018) advertem, entretanto, que os relacionamentos prévios e a confiança, em vez de serem antecedentes, são condições necessárias para permitir a demanda de serviços de consultoria. Mostra-se, dessa maneira, relevante observar o papel do próprio contador em gerar a confiança necessária que demonstre sua habilidade, necessidade e utilidade da consultoria contábil, fazendo com que seus clientes, de fato, procurem por seus serviços.

\section{DELINEAMENTO DA PESQUISA}

\subsection{CARACTERIZAÇÃO DA PESQUISA E DESCRIÇÃO DA AMOSTRA}

A pesquisa, quanto aos objetivos, classifica-se como descritiva, pois tem como finalidade a descrição de características relativas à consultoria contábil às MPEs (MARTINS \& THEÓPHILO, 2009). Em relação ao procedimento, a pesquisa caracteriza-se como entrevista semiestruturada, com base no estudo de Silva (2015), no qual a autora retrata como motivos para a escolha da entrevista semiestruturada a heterogeneidade do setor e a falta de 
Oliveira, Miranda e Takamatsu (2021)

Sustentabilidade em Micro e Pequenas Empresas: A Visão do Contador

resposta a questionários. Segundo Trivinõs (1987), a entrevista semiestruturada favorece não apenas a descrição dos fenômenos sociais, mas também sua explicação e a compreensão de sua totalidade, além de manter a presença consciente e atuante do pesquisador no processo de coleta de informações. Não obstante, a entrevista semiestruturada possibilita respostas espontâneas devido à proximidade entre o entrevistador e o entrevistado, além de uma cobertura mais profunda sobre o assunto mediante sua elasticidade quanto à duração (TRIVINÕS, 1987). Por fim, quanto à abordagem do problema, a pesquisa classifica-se como qualitativa, uma vez que busca descrever e compreender as características inerentes à consultoria contábil às MPEs. (MARTINS; THEÓPHILO, 2009).

A amostra deste trabalho, mediante a acessibilidade, se dá com a participação de 12 (doze) profissionais representantes de escritórios contábeis os quais têm entre seus clientes Micro e Pequenas Empresas. As entrevistas semiestruturadas foram realizadas em Março e Junho de 2018. Ressalta-se que os achados não podem ser generalizados, visto a especificidade de cada entrevistado.

A escolha da amostra se justifica devido ao papel desempenhado pelos contadores junto às MPEs, que, atuando diariamente com estas entidades, adquirem maiores oportunidades de identificar suas necessidades e auxiliá-las em busca de soluções, por meio da consultoria contábil.

\subsection{COLETA DE DADOS}

Os dados foram coletados através de doze entrevistas semiestruturadas, com perguntas previamente formuladas, sendo abertas e fechadas, possibilitando a comparação entre as respostas obtidas, conforme o Quadro 3.

Quadro 3 - Roteiro de Entrevista.

\begin{tabular}{|c|c|c|}
\hline Perguntas & \multicolumn{2}{|c|}{ Especificidades } \\
\hline \multicolumn{3}{|l|}{ Qual a sua idade? } \\
\hline \multicolumn{3}{|l|}{ Qual a sua formação acadêmica? } \\
\hline \multicolumn{3}{|l|}{ Há quanto tempo obteve sua formação acadêmica? } \\
\hline Você fez, faz ou pretende fazer alguma especialização/atualização na contábil? & SIM & NÃO \\
\hline \multicolumn{3}{|l|}{ Em caso positivo, qual especialização/atualização? } \\
\hline \multicolumn{3}{|l|}{ Há quanto tempo você atua na área? } \\
\hline Você se sente valorizado (a) pelos seus clientes quanto a profissional contábil? & SIM & $\mathrm{NÃO}$ \\
\hline \multicolumn{3}{|l|}{ Por que você se sente ou não se sente valorizado pelos seus clientes? } \\
\hline \multicolumn{3}{|l|}{ Há quanto tempo existe o escritório contábil? } \\
\hline \multirow{2}{*}{\multicolumn{3}{|c|}{$\begin{array}{l}\text { Poderia apresentar a empresa? } \\
\text { Qual o porte do escritório? }\end{array}$}} \\
\hline & & \\
\hline \multicolumn{3}{|l|}{ A maioria dos clientes são Micro e Pequenas Empresas (MPEs)? } \\
\hline \multicolumn{3}{|l|}{ Em caso afirmativo, sabe qual o percentual aproximado de proporção? } \\
\hline $\begin{array}{l}\text { Sabe informar o percentual aproximado de fechamento de MPEs efetuados pelo escritório } \\
\text { anualmente? }\end{array}$ & SIM & NÃO \\
\hline \multicolumn{3}{|l|}{ Em caso positivo, qual o percentual de fechamento? } \\
\hline \multicolumn{3}{|l|}{ A que atribui o fechamento destas empresas? } \\
\hline $\begin{array}{l}\text { Acredita que a prestação de consultoria contábil antes da abertura, como um planejamento } \\
\text { do negócio, contribuiria para uma maior sobrevivência destas empresas? }\end{array}$ & SIM & NÃO \\
\hline O escritório oferece a consultoria contábil a estas empresas? & SIM & $\mathrm{NÃO}$ \\
\hline \multicolumn{3}{|l|}{ Em caso positivo, como este serviço é prestado? } \\
\hline \multicolumn{3}{|l|}{ Quais problemas o escritório enfrenta ao oferecer e/ou prestar este tipo de serviço? } \\
\hline \multicolumn{3}{|l|}{$\begin{array}{l}\text { Entre estes serviços, a qual deles atribui a maior importância para sobrevivência de uma } \\
\text { MPE? }\end{array}$} \\
\hline \multicolumn{3}{|l|}{ E quais são efetivamente solicitados pelos clientes? } \\
\hline E no caso de uma capacitação em gestão para o proprietário da MPEs, acredita ser eficiente? & SIM & $\mathrm{NÃO}$ \\
\hline \multicolumn{3}{|l|}{ Por que acredita ou não ser eficiente a capacitação em gestão para o proprietário? } \\
\hline $\begin{array}{l}\text { Alguma observação particular para futuros contadores que desejam atuar no ramo da } \\
\text { consultoria contábil às MPEs? }\end{array}$ & & \\
\hline
\end{tabular}

Fonte: Elaborado pelos autores com base no estudo de Silva (2015). 


\subsection{PROCEDIMENTO METODOLÓGICO}

Para interpretação dos dados foi realizada a análise de conteúdo, que é considerada por Bardin (2010) como um conjunto de técnicas de análise de comunicações, a qual tem como função primordial o desvendar crítico. Contempla três processos necessários: a pré-análise, a exploração do material, e o tratamento de resultados juntamente com a inferência e a interpretação. Na pré-análise tem-se a organização do material que será analisado, e, consequentemente, o objetivo de transformá-lo em operacional, e a sistematização de ideias preliminares. No segundo processo, a exploração do material tem como elementos primordiais a codificação, classificação e categorização. Além disso, é tida como fase de descrição analítica, onde remete-se ao material textual coletado, submetido a um detalhado estudo e orientado pela revisão da literatura e de hipóteses. O terceiro processo remete tanto ao tratamento dos resultados quanto à inferência e interpretação. Nele ocorrem as interpretações inferenciais, a partir dos resultados tratados, e a condensação e ênfase das informações analisadas. É este o momento de intuição, da análise reflexiva e da crítica (BARDIN, 2010).

\section{RESULTADOS}

\subsection{PERFIL DOS RESPONDENTES}

Em uma etapa inicial, foram analisadas as variáveis relativas ao perfil dos entrevistados, como sexo, idade, formação acadêmica e tempo de aquisição, especialização / continuação dos estudos e tempo de atuação profissional na área.

Quando analisados os perfis e características do conjunto de entrevistados, verificou-se que $58,33 \%$ (7) são representantes do sexo masculino e 41,67\% (5) são representantes do sexo feminino, cujas idades figuram-se entre 21 e 76 anos, conforme o Gráfico 1, abaixo, sendo que a maioria - 66,67\% (8) - encontra-se na faixa etária entre 21 e 40 anos.

Gráfico 1 - Histograma com a Distribuição de Idade dos Entrevistados.

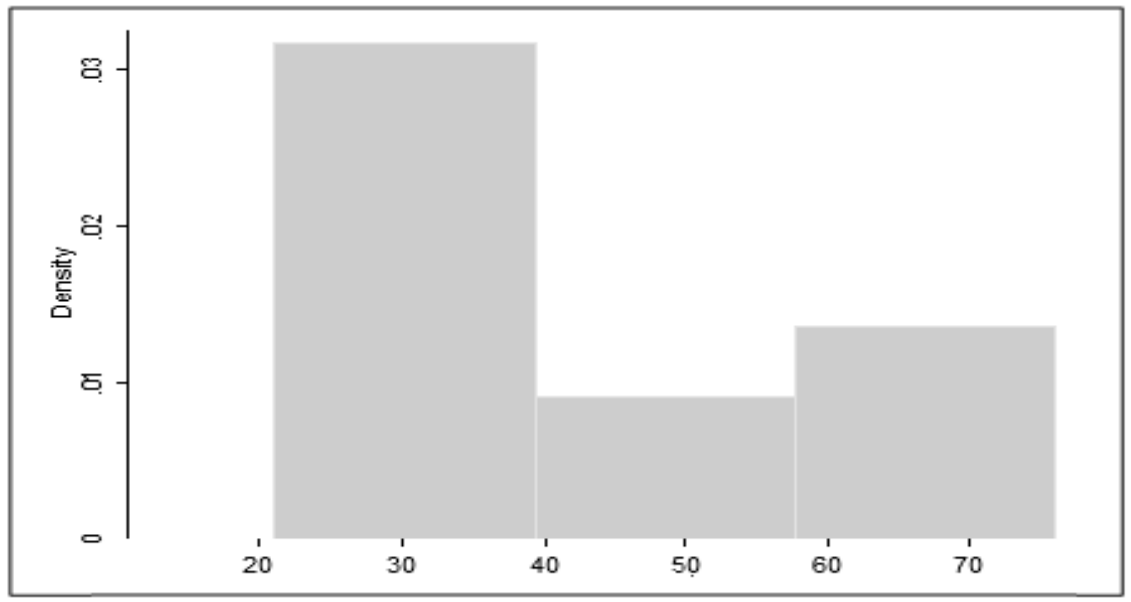

Fonte: Elaborado pelos autores.

Os entrevistados informaram já possuir curso superior finalizado, ou em processo de finalização, estando elencado o curso de Ciências Contábeis com um maior percentual representativo, de 83,33\% (10). Quando questionados acerca de especialização / continuação dos estudos, 75\% (9) informaram que já fizeram ou estão fazendo algum tipo de especialização. Consoante à aprendizagem e educação continuada por parte dos profissionais contábeis, Carneiro e Dall'Agnol $(2005,2004)$ discorrem que a justificativa para a aprendizagem se encontra, principalmente, na essência da contribuição que pode ser realizada pelo profissional contábil ao setor econômico quanto ao auxílio na contenção da mortalidade de empresas. Ademais, é fator indispensável em uma mudança econômica e ocasiona um significativo reflexo social. 
Não obstante, o tempo de experiência profissional na área dos entrevistados se mostrou bastante pulverizado, com o mínimo de 2 anos e o máximo de 43 anos, encontrando-se a maioria percentual de 75\% (9) entre 2 e 20 anos de experiência. Donadone et al. (2012), ao abordarem em seu estudo a Orientação Empresarial desenvolvida pelo SEBRAE-SP, enfatizam que a experiência adquirida durante os anos de atuação junto as PMEs viabilizam o aprofundamento de conhecimento sobre este universo, possibilitando uma adaptação de ferramental acadêmico, bem como de soluções gerencias para o ambiente destas empresas. Esta experiência é um facilitador para um alinhamento do conhecimento prático com o teórico, assim, permitindo o desenvolvimento não somente de produtos que atendam às demandas das pequenas empresas, mas também que possam produzir conhecimento sobre este universo.

Verificou-se que 83,33\% (10) dos profissionais entrevistados se sentem valorizados pelos seus clientes como profissionais contábeis. Cabendo ainda um trecho da entrevista com o Entrevistado 8, que ressalta a importância do profissional contábil ao dizer que "os clientes recorrem a contabilidade em busca de soluções para problemas, pedido opinião. Eles precisam e confiam no contador".

Os $16,67 \%$ (2) dos profissionais entrevistados que não se sentem valorizados como profissionais contábeis destacaram como razões a remuneração percebida e fato de que, em determinados cenários, os clientes não valorizam sua atuação, pois, na visão destes entrevistados, as pessoas normalmente não entendem o que um contador faz.

\subsection{ANÁLISE DOS RESULTADOS}

Posteriormente à análise das variáveis relativas ao perfil dos entrevistados, foram analisadas as variáveis relativas ao perfil dos escritórios, como porte, tempo de abertura e tipo de clientes. A distribuição dos escritórios por porte está demonstrada no Gráfico 2 abaixo:

Gráfico 2 - Distribuição dos Escritórios por Porte

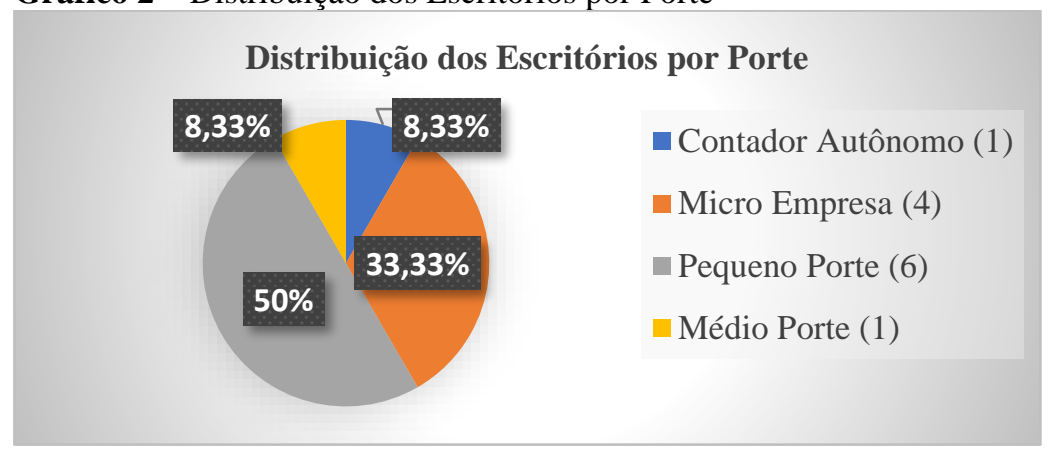

Fonte: Elaborado pelos autores.

Consonante com a variável porte, identificada, foi o tempo de abertura destes escritórios, onde o mínimo de tempo de existência encontrado foi de 1 ano e o máximo de 50 anos, ambos em empresas de pequeno porte. O escritório do contador autônomo tem existência de 29 anos e o de médio porte de 15 anos. Já os escritórios com porte de microempresas apresentaram tempo de existência mínimo de 9 anos e máximo de 30 anos. Estes escritórios, com múltiplos portes, estão consolidados no mercado contábil, em geral, há bastante tempo, o que possibilita uma maior propriedade nas respostas acerca do tema abordado nesta pesquisa, mediante a experiência adquirida.

Destaca-se que dos doze escritórios entrevistados, conforme Gráfico 3, abaixo, 83,33\% (10) possuem, predominantemente, como clientes Micro e Pequenas Empresas, cabendo frisar que os entrevistados 4, 10 e 11 não souberam informar o percentual aproximado de MPEs, e que os entrevistados 4 e 11 informaram que as MPEs não são a maioria entre os clientes que possuem. Este cenário demonstrou percentuais destes clientes na média de $91 \%$, ensejando ainda maior expertise acerca das especificidades desta população e, consequentemente, maior presunção de domínio sobre o tema. 
Oliveira, Miranda e Takamatsu (2021)

Sustentabilidade em Micro e Pequenas Empresas: A Visão do Contador

Gráfico 3 - Percentual Aproximado de MPEs por Escritório.

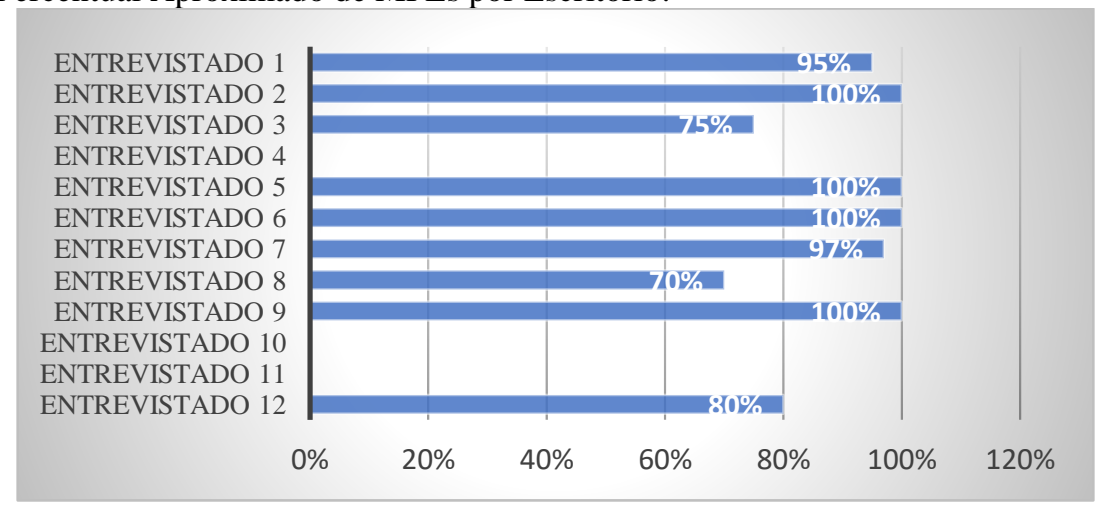

Fonte: Elaborado pelos autores.

Adentrando ao objeto relacionado ao fechamento e causa da mortalidade das MPEs, averiguou-se que oito $(66,67 \%)$ dos doze entrevistados sabem o percentual médio aproximado de fechamento destas empresas anualmente. Dentre os oito respondentes, o percentual mínimo encontrado foi de $0 \%$ e o máximo foi de $30 \%$, apurando, assim, que estes escritórios perdem, anualmente, em média, 7\% dos seus clientes MPEs para a mortalidade. Esta realidade média apresentada pelos entrevistados se mostra, de certa maneira, razoável, quando confrontada aos dados do SEBRAE (2016), cuja taxa de mortalidade para MPEs criadas em 2012 foi elencada no percentual de $23,4 \%$. Dentre as principais causas apontadas pelos entrevistados para o fechamento destas entidades, conforme demonstrado na Tabela 2, a seguir, configuraram-se:

Tabela 2: Causas para o Fechamento dos clientes MPEs

\begin{tabular}{l|c}
\hline \multicolumn{1}{c|}{ Causas } & Percentual de Representação \\
\hline Burocracias relativas ao mercado & $25 \%$ \\
\hline Dificuldades financeiras enfrentadas pelas empresas & $19 \%$ \\
\hline Alta carga tributária & $19 \%$ \\
\hline Incapacidade de gestão do empreendedor & $13 \%$ \\
\hline Situação econômica do país & $13 \%$ \\
\hline Mudança de ramo e/ou porte da entidade & $13 \%$ \\
\hline
\end{tabular}

Fonte: Elaborado pelos autores.

Com percentual de $25 \%$, as burocracias relativas ao mercado se destacaram como uma das principais causas para a mortalidade de uma MPE. A falta de preparo para atuação no mercado, citada pelo Entrevistado 2, bem como a diminuição da demanda no mercado, tanto de serviço quanto de comércio, citada pelo Entrevistado 10, figuram entre os fatores que levam estas empresas ao fechamento precoce.

O resultado atinente às burocracias relativas ao mercado se mostrou em consonância com os trabalhos apresentados pelos autores estudados (ORTIGARA et al., 2006; ALBUQUERQUE E FILHO, 2012), destacando-se o relatado por Bonacim, Cunha e Corrêa (2009), cujos resultados demonstraram que houve um consenso entre os empreendedores a respeito de que, antes da abertura de qualquer negócio, eles deveriam procurar ajuda profissional para conhecer mais sobre o mercado e os riscos enfrentados, proceder à análise da concorrência e estimar com mais precisão o capital necessário para a abertura do negócio e para giro.

Relativo à segunda causa principal, na visão dos entrevistados, estão as dificuldades na administração financeira da empresa, com um percentual de $19 \%$ de representação, cujos entrevistados 1, 3, 9 e 12 ressaltaram que, comumente, os empresários confundem o dinheiro dos sócios com o da empresa e que, muitas vezes, não têm noção de administração. Conforme anteriormente citado por Berti (2012), estas empresas podem ser beneficiadas pela contabilidade, por meio de fornecimento de um relatório que contenha diagnósticos e 
recomendações à administração da entidade. Para mais, é essencial que os serviços sejam estendidos com o objetivo da absorção das recomendações.

O fator carga tributária se fez presente como um dos principais motivos para o fechamento de MPEs nas pesquisas dos autores Ortigara et al. (2006) e Bonacim, Cunha e Corrêa (2009). Neste estudo, foi apresentado um percentual de $19 \%$ de representação na opinião dos entrevistados, além de evidenciado pelos entrevistados 6,8 e 11, onde este último enfatizou que "os clientes não suportam a carga tributária nacional".

A incapacidade de gestão do empreendedor elencou as causas do fechamento de MPEs, apresentado uma participação percentual de $13 \%$, no entanto, não menos importante que as demais. Quando questionados acerca da eficiência da capacitação em gestão, por parte do proprietário, para auxílio na sobrevivência das empresas, $100 \%$ dos entrevistados se mostraram favoráveis e ainda apontaram como sendo importantíssimo para o desenvolvimento do negócio. Este foi um dos pontos que mais chamou a atenção dos entrevistados durante o percurso da entrevista e cabe o destaque e relatório dos pronunciamentos:

Entrevistado 4: Por falta de conhecimento especializada (gestão) por parte dos proprietários, eles comentem muitos erros, principalmente relacionados à compra/venda de mercadorias, sem conhecimento se a transação vai obter lucro ou prejuízo.

Entrevistado 8: Uma especialização ajudaria muito.

Entrevistado 9: O cliente tem que estar aberto a querer buscar o conhecimento.

Entrevistado 10: Com certeza, seria importantíssimo, tanto para gerir quanto para discutir com a própria contabilidade. Também para entendimento das informações que a contabilidade passa. Enfim, "abrir a cabeça" para a forma gestora.

Entrevistado 11: O dono da empresa deixa na mão de outras pessoas, tem que ter uma visão ampla do que acontece na empresa.

Entrevistado 12: Para que ele possa visualizar o sonho como um verdadeiro negócio, possa efetivamente realizar um plano de negócios. Também para capacitação com o intuito de gerir o próprio negócio (financeiro, pessoal, vendas).

O resultado exposto pode asseverar o discorrido pelos diversos autores ao longo do referencial teórico (KASSAI, 1997; CARNEIRO E DALL'AGNOL 2005, 2004; PETRY E NASCIMENTO, 2009; SEBRAE, 2016), em especial, por Ferreira et al. (2012), que, no estudo realizado com o objetivo de apontar quais são os principais fatores associados com a mortalidade das micro e pequenas empresas, constatou o baixo nível de escolaridade do empreendedor e competência gerencial diminuta.

Reconhecidas, também, pelos entrevistados como uma das principais causas para a mortalidade destas entidades estão a situação econômica do país e a mudança de ramo e/ou porte da entidade, cada uma com um percentual de representação de 13\%. Em complementação ao aludido cenário de mortalidade das MPEs, descrito pelos profissionais representantes dos escritórios contábeis, o Entrevistado 1 atribui o fechamento de MPEs à falta de experiência do empresário no mercado, falta de boa assessoria, falta de capital e falta de especialização por parte do proprietário.

Prosseguindo às entrevistas, foram analisadas as variáveis relativas aos serviços, a maneira e as dificuldades enfrentadas na prestação da consultoria contábil. Partindo do questionamento inicial aos entrevistados, foram inqueridos se acreditam que a prestação de consultoria contábil, antes da abertura da empresa, como um planejamento do negócio, contribuiria para uma maior sobrevivência destas entidades.

O questionamento supracitado não somente teve um percentual de respostas favoráveis de $100 \%$, como também despertou grande interesse por parte dos entrevistados, à medida que direcionaram parte significativa da entrevista para reflexão e discussão do tema. Seguem transcritos alguns dos relatos quanto ao planejamento prévio dos negócios em subsídio à sobrevivência de MPEs:

Entrevistado 1: O planejamento do negócio antes da abertura é muito importante e deve ser feito, por exemplo, utilizando de análise do mercado, conjectura financeira 
do país e análise do investimento. A consultoria auxilia nestes aspectos e proporciona o melhor caminho.

Entrevistado 2: É extremamente importante uma consultoria antes da abertura de qualquer tipo de negócio, pois é possível a entidade ou responsável pela abertura ter uma melhor noção se seu negócio será viável ou não.

Entrevistado 7: É muito importante o planejamento tributário antes da abertura da empresa, bem como local e público a ser atingido.

Entrevistado 10: Tanto no sentido financeiro, quanto no econômico, tem que ter planejamento prévio. O planejamento ajuda a organizar a empresa.

Exprimindo suas opiniões sobre o planejamento antes da abertura da empresa, Bonacim, Cunha e Corrêa (2009) indicam como causa da mortalidade de MPEs um conjunto de fatores associados que, acumulados, contribuem para o fenômeno, e, dentre os fatores principais, está a falta de planejamento prévio. Em companhia, o SEBRAE (2016) reconhece o planejamento adequado do negócio, antes de sua abertura, também como fator contribuinte para a sobrevivência e manutenção das MPEs, o que denota o alinhamento das respostas aferidas dos doze entrevistados aos estudos ora citados.

O próximo tópico indagado nas entrevistas foi se os escritórios oferecem a consultoria contábil e como este serviço é prestado. Computou-se que apenas $25 \%$ (3) dos entrevistados não oferecem o serviço de consultoria contábil aos clientes MPEs, e a maioria, 75\% (9), respondeu que o serviço comumente é prestado da seguinte maneira:

- Auxílios informais;

- Questionamentos do porquê do negócio, se o produto tem cliente, tem mercado, se é isso mesmo que o cliente deseja. Posteriormente trabalham em cima das respostas buscando soluções para os clientes;

- Consultoria antes da abertura, planejamento e fase inicial;

- Auxílio em trabalho de gestão e orientação para continuidade;

- Revisão e análise dos pontos fortes e fracos da empresa;

- Processamento mensal, consultoria gerencial baseada na contabilidade tanto financeira, quanto gerencial;

- Planejamento tributário e gerencial.

Dentre as principais dificuldades encontradas na prestação do serviço de consultoria contábil às MPEs, relatadas pelos entrevistados, sobressaíram:

- O cliente não quer que o contador saiba o quanto ele ganha, na realidade;

- Administrar o pessoal da empresa;

- O empresário confunde/mistura o que é dele com o que é da empresa;

- Inexperiência dos clientes;

- Cliente não enxerga da mesma maneira que a contabilidade, o cliente discorda e não aceita opiniões, tem resistência;

- Muitos clientes fazem o orçamento, mas não fecham o contrato com o escritório;

- Acessibilidade da informação, o cliente não conta tudo para o contador;

- Falta de organização interna do cliente;

- O cliente, às vezes, não compreende o que a empresa passa, principalmente quanto aos impostos.

- Os clientes acreditam que qualquer coisa que saia do controle deles os tornam mais vulneráveis ao insucesso.

Ao verificar estas dificuldades, confrontá-las com os trabalhos catalogados durante esta pesquisa e confirmá-las com os pensamentos anteriores de Berti (2012), coube retomar às orientações do autor, que apontaram, dentre os motivos que levam os empresários a não quererem contratar as atividades de um consultor, o receio de fracasso, onde a contratação de um consultor simbolizaria o reconhecimento deste fracasso, ou seja, a sua incompetência na 
gerência do próprio negócio. Ademais, o autor ainda ressalta a necessidade da existência de alto grau de confiança, para que não haja o truncamento de informações, e enfatiza a relevância do consultor, não apenas como conselheiro, mas que, ao utilizar de sua experiência e formação generalista, possa visualizar os problemas existentes e suprir às necessidades de seus clientes. Embora testemunhadas as dificuldades para a prestação do serviço de consultoria contábil às MPEs, os entrevistados salientaram a importância de uma consultoria contábil para a sobrevivência de uma empresa e destacaram os seguintes serviços:

- Análise de Custos;

- Planejamento gerencial;

- Planejamento tributário;

- Planejamento orçamentário;

- Planejamento financeiro;

- Reeducação financeira, de pessoal e de compra/venda;

- Estudar o perfil do cliente, identificar o problema e apresentar uma solução;

- Realização da consultoria mostrando a geração de valor para o cliente, com foco no resultado.

No que concerne aos serviços de consultoria contábil acima listados, nota-se uma predominância relativa à consultoria direcionada ao planejamento, seja ele gerencial, tributário ou financeiro. Este mesmo fator foi verificado na literatura que indica principais causas de mortalidade das empresas, paralelamente às principais formas de contribuição a estas entidades, elencadas pelos autores (DUTRA E PREVIDELLI, 2003; BONACIM, CUNHA E CORRÊA, 2009; ORTIGARA ET AL., 2011; FERREIRA ET AL., 2012; ALBUQUERQUE E FILHO, 2012; SANTOS E MIRANDA, 2017; VANNUCCI, 2017).

Destarte, Sá (2008) realça que o consultor contábil deve oferecer ao cliente orientações e opiniões latentes para o alcance dos referidos propósitos destas entidades. Todavia, apesar de os serviços contábeis de consultoria terem sido destacados pelos entrevistados como importantes para a sobrevivência de uma MPE, a realidade retratada pela população entrevistada demonstrou que, muitas vezes, os empresários não demandam oficialmente a consultoria contábil e, outras vezes, quando a necessitam, eles buscam aconselhamento junto ao SEBRAE.

Uma vez que estes empreendedores procuram o auxílio de um dos profissionais contábeis entrevistados, os serviços de consultoria contábil buscados, efetivamente, por eles são:

- Administração de pessoal;

- Planejamento tributário;

- Análise de mercado;

- Auxílio em gestão financeira;

- Informações gerenciais para tomada de decisões.

Dado as especificidades contidas nas solicitações dos clientes MPEs dos profissionais entrevistados, observou-se que grande parte das MPEs buscam o profissional contábil unicamente com o intuito de cumprimento de obrigações acessórias, como contabilizações de eventos e transações, objetivando o cumprimento de exigências tributárias e fiscais.

Realce para a fala do Entrevistado 10, que, ao aludir a consultoria contábil solicitada pelos clientes, relacionando-a, principalmente, aos avanços ocorridos na área contábil e na sociedade, de forma geral, menciona que:

O principal não é o conhecimento técnico contábil. O principal é "abrir a cabeça" para muito mais do que a contabilidade em si.

A contabilidade está cada vez mais gerencial, principalmente na área de consultoria. Assim, deve-se ter uma visão maior, agregando os diversos pontos da contabilidade para auxílio na tomada de decisões. 
Os clientes estão buscando muito mais do que apenas registros. Eles buscam o auxílio na contabilidade para a tomada de decisões.

Isto posto, por intermédio da análise de conteúdo, aplicada à entrevista semiestruturada, foi possibilitado o alcance de respostas que demonstraram o perfil dos contadores, dos escritórios de contabilidade e dos clientes MPEs, bem como os serviços, a maneira e as dificuldades enfrentadas na prestação da consultoria contábil.

A análise dos dados possibilitou a aferição do perfil dos contadores, dos escritórios de contabilidade e dos clientes MPEs, bem como os serviços, a maneira e as dificuldades enfrentadas na prestação da consultoria contábil. Dentre os resultados encontrados, destacaramse os seis fatores principais para o fechamento de MPEs, apresentados pelos entrevistados: Burocracias relativas ao mercado; Dificuldades financeiras enfrentadas pelas empresas; Alta carga tributária; Incapacidade de gestão do empreendedor; Situação econômica do país; e Mudança de ramo e/ou porte da entidade.

De acordo com os entrevistados, os serviços que apresentam maior contribuição para o combate aos fatores de mortalidade supracitados são a análise de custos, planejamento gerencial, planejamento tributário, planejamento orçamentário, planejamento financeiro, reeducação financeira, de pessoal e de compra/venda, estudo do perfil do cliente, bem como a identificação do problema e apresentação de solução, e, por último, a realização da consultoria, mostrando a geração de valor para o cliente, com foco no resultado.

Dentre as principais dificuldades encontradas na prestação do serviço de consultoria contábil às MPEs, relatadas pelos entrevistados, sobressaíram a falta de organização interna do cliente, acessibilidade e truncamento de informações, confusão entre o patrimônio do empresário e o patrimônio da empresa, inexperiência dos clientes, falta de alinhamento de metas entre a empresa e a contabilidade, e o receio do fracasso pelo empresário. Todos os respondentes destacaram o serviço de consultoria contábil direcionado ao planejamento prévio, antes da abertura do negócio, como uma maneira eficiente de aumento da taxa de sobrevivência de MPEs, onde ratificaram a importância deste modo de planejamento e acrescentaram que proporciona a organização da empresa para a execução e direção de suas atividades.

Ao presente estudo, foram encontradas limitações relativas à acessibilidade para as entrevistas, onde deparou-se com a impossibilidade de contatos com os profissionais representantes de escritórios contábeis. Portanto, os resultados ficam restritos à amostra estudada, que foi selecionada por conveniência, de acordo com a acessibilidade e disponibilidade dos elementos da população.

\section{CONSIDERAÇÕES FINAIS}

Notáveis são as Micro e Pequenas Empresas (MPEs) para o desenvolvimento e crescimento econômico e social do país, pois representam um grande aporte de geração de emprego e renda. Contudo, suas atividades, muitas vezes, são extintas em curto espaço de tempo por múltiplos fatores, entre eles, essencialmente, os ligados às questões gerenciais. A gestão centralizada na figura do empresário destas entidades traz consigo a necessidade de uma avaliação de sua contribuição para a taxa de sobrevivência destas empresas.

Juntamente às MPEs, encontram-se os contadores, que, em determinados momentos, foram vistos apenas como executores de obrigações acessórias e cumprimentos legais, e atualmente, vêm se destacando como potenciais consultores destas entidades, mediante sua proximidade e experiência de atuação. A consultoria direcionada às MPEs busca atender às particularidades deste segmento, e o profissional contábil, enquanto possuidor de condições técnicas, tem a possibilidade de fornecer tanto aconselhamento quanto auxílio, de forma prática, a estas entidades, para que estas consigam obter um melhor desempenho em seus negócios e manutenção de suas atividades. 
Portanto, o objetivo do trabalho consistiu em avaliar a percepção dos contadores acerca da sustentabilidade em MPE e como a consultoria contábil poderia auxiliar estas empresas na manutenção de suas atividades. Esta pesquisa contou com a participação de doze (12) profissionais, representantes de escritórios contábeis, que foram selecionados com base tanto em acessibilidade quanto em suas experiências profissionais.

Os resultados apontaram como as 6 principais causas dos altos índices de mortalidade enfrentados pelas MPEs, na visão dos entrevistados: burocracias relativas ao mercado; dificuldades financeiras enfrentadas pelas empresas; alta carga tributária; incapacidade de gestão do empreendedor; situação econômica do país; e mudança de ramo e/ou porte da entidade. Ainda, observou-se que estes índices podem ser amenizados por meio da prestação do serviço de consultoria contábil, principalmente no que tange ao planejamento prévio, antes da abertura da empresa. Para os respondentes, a consultoria contábil permite a organização da empresa para a execução e direção de suas atividades.

A expertise do Contador, não somente associada às questões técnicas e operacionais, mas que proporciona uma maior compreensão da realidade do negócio, por meio da análise da situação econômica e patrimonial da entidade, do conhecimento de procedimentos gerenciais e de controle, pode auxiliar as empresas em melhores práticas e que, no longo prazo, poderiam afetar a capacidade de sobrevivência das mesmas. A alteração na normatização contábil, ocorrida a partir de 2010, com a adoção das normas internacionais, gerou uma valorizado do papel do contador, da figura do subjetivismo responsável e, portanto, da capacidade de julgamento dos profissionais da área. Contudo, ela, por si só, não é capaz de alterar a mentalidade desse profissional.

A pandemia do COVID-19, decretada pela Organização Mundial da Saúde (OMS), em 11 de março de 2020 (WORLD HEALTH ORGANIZATION, 2020), trouxe mudanças significativas e desafios para a profissão contábil. Em momentos como esse, são evidenciadas descobertas e avanços tecnológicos que alteram significativamente todas as áreas. O estímulo à migração ao meio digital gerou um incremento do percentual de documentação eletrônica (que não em meio físico) e automatização de processos. O estímulo ao trabalho remoto, por sua vez, aumentou a concorrência, uma vez que serviços, antes restritos à mesma cidade de origem da empresa contratante, agora não são mais restritos em termos de localidade. Uma transição, que já vinha ocorrendo no século XXI, além de possibilidades preexistentes à pandemia, foram alavancadas por uma mudança de cultura, que afetou a aceitação e sedimentação de processos que antes eram vistos com desconfiança.

Portanto, percebe-se, nesse cenário, a importância de o Contador assumir a posição de consultor, diante da base oferecida pelos conhecimentos da estruturação e geração de informações contábeis. Avaliar a importância da consultoria atribuída somente sob a visão dos Contadores, portanto, é uma limitação da pesquisa, uma vez que, a utilização da consultoria pode ser influenciada pela oferta desse tipo de serviço. Mostra-se, portanto, relevante para a literatura da área compreender se há oferta de serviços contábeis e quais os desafios por trás da realização desses serviços, o que somente pode ser compreendido com o acesso aos usuários dessa informação, quais sejam, os clientes. A concatenação dos achados, e o contraponto das diferentes partes interessadas, poderia evitar vieses de uma das partes da relação. Portanto, metodologias diversas da técnica de entrevista, como o emprego de um grupo focal, poderiam gerar a contribuição de experiências e conhecimentos diversos, no exercício de compreender a realidade. Ainda, sugere-se que sejam realizadas pesquisas futuras que avaliem temáticas que incluem: a tecnologia aliada à contabilidade e sua aplicação em MPEs, a educação continuada para profissionais contábeis, as Normas Brasileiras de Contabilidade, em consonância com o International Financial Reporting Standards (IFRS), aplicadas à contabilidade de MPEs, e como estas normas têm impactado na sobrevivência destas entidades. 


\section{REFERÊNCIAS}

ALBUQUERQUE, A. F.; ESCRIVÃO FILHO, E. Fatores de mortalidade de pequenas empresas. Anais. VII EGEPE -Encontro de Estudos sobre Empreendedorismo e Gestão de Pequenas Empresas. Florianópolis, 2012. Disponível em < http://www.anegepe.org.br/javabusca/files/t16720200024_1.pdf>. Acesso em: 21 nov. 2017.

BARDIN, L. Análise de conteúdo. Tradução Luís Antero Reto e Augusto Pinheiro. Lisboa: Edições 70, 2010.

BERTI, A. Consultoria e Diagnóstico Empresarial - Teoria e Prática. $2^{\mathrm{a}}$ ed. Curitiba: Juruá, 2012.

BLACKBURN, R.; CAREY, P.; TANEWSKI, G. Business advice by accountants to SMEs: relationships and trust. Qualitative Research in Accounting \& Management, 2018.

BONACIM, C. A. G.; CUNHA, Julio Araújo Carneiro da; CORRÊA, Hamilton Luiz. Mortalidade dos empreendimentos de micro e pequenas empresas: causas e aprendizagem. Gestão \& Regionalidade, v. 25, n. 74, 2009. Disponível em: < http://www.redalyc.org/pdf/1334/133412626006.pdf> Acesso em: 21 nov. 2017

CARNEIRO, J. D.; DALL'AGNOL, R. M. A consultoria em gestão realizada pelo contabilista como alternativa de redução da mortalidade das MPE. Revista Catarinense da Ciência Contábil, v. 4, n. 10, p. p. 09-23, dez. 2004/mar. 2005. ISSN 2237-7662. Disponível em: <http://revista.crcsc.org.br/index.php/CRCSC/article/view/1134>. Acesso em: 31 ago. 2017.

CONSELHO FEDERAL DE CONTABILIDADE (CFC). Profissionais Ativos nos

Conselhos Regionais de Contabilidade. [s.1.: s.n], 2017. Disponível em:

<http://www3.cfc.org.br/spw/crcs/ConselhoRegionalAtivo.aspx> Acesso em: 18 out. 2017.

CONSELHO REGIONAL DE CONTABILIDADE DO ESTADO DE SÃO PAULO

(CRCSP). Manual de Técnicas e Práticas de Consultoria Contábil junto às Pequenas e Médias Empresas. São Paulo: CRCSP, 2011. Disponível em:

<http://www.crcrs.org.br/arquivos/livros/crcsp_m05.pdf?6edb3c> Acesso em: 24 out. 2017.

DONADONE, J. C.; SILVEIRA, F. Z.; RALIO, V. R. Z. Consultoria para pequenas e médias empresas: as formas de atuação e configuração no espaço de consultoria brasileiro. Gestão de Produção. São Carlos, v. 19, n. 1, p. 151-171, 2012. Disponível em: <

http://www.scielo.br/pdf/gp/v19n1/a11v19n1.pdf> Acesso em: 21 out. 2017

FERREIRA, L. F. F. et al. Análise quantitativa sobre a mortalidade precoce de micro e pequenas empresas da cidade de São Paulo. Gestão e Produção, v. 19, n. 4, p. 811-823, 2012. Disponível em: <http://www.scielo.br/pdf/gp/v19n4/a11v19n4> Acesso em: 31 ago. 2017.

KUBR, M. , Management Consulting, A Guide for the Profession, GENEVA: International Labour Organisation, 1986.

LEMES, A. ; PISA, B. Administrando micro e pequenas empresas. Rio de Janeiro: Elsevier Brasil, 2010.

MARTINS, G. D. A.; THEÓPHILO, C. R. Metodologia da investigação cientifica. São Paulo: Atlas, 2009.

NEITZKE, A. C. A. ; OLIVEIRA, R. M. Um estudo dos fatores que influenciam o processo de gestão das micro e pequenas empresas gaúchas. In: CONGRESSO USP

CONTROLADORIA E CONTABILIDADE, 14, 2014, São Paulo. Anais. São Paulo: s.n., 2014, s.p. Disponível em: 
<http://www.congressousp.fipecafi.org/anais/artigos142014/107.pdf > Acesso em: 31 ago. 2017

OGANE, Y. Who is a good advisor for entrepreneurs? Applied Economics, v. 53, n. 1, p. 134, 2021.

OOSTHUIZEN, A. et al. Predicting the benefits that small business owners obtain from their accounting practitioners. 2018. Tese de Doutorado. University of Pretoria.

ORTIGARA, A. Â. et al. Causas que condicionam a mortalidade e/ou o sucesso das micro e pequenas empresas no estado de Santa Catarina. Tese (doutorado) - Universidade Federal de Santa Catarina, Centro Tecnológico. Programa de Pós-Graduação em Engenharia de Produção. Florianópolis, Santa Catarina. 2006. Disponível em:

$<$ https://repositorio.ufsc.br/xmlui/bitstream/handle/123456789/89556/234224.pdf?sequence= 1\&isAllowed=y> Acesso em: 21 nov. 2017.

PEREIRA, L. CRCPI discute criação de Fórum Municipal das Micro e Pequenas Empresas em reunião. Conselho Federal de Contabilidade (CFC). 12 Abr. 2017. Disponível em: $<$ http://cfc.org.br/noticias/crcpi-discute-criacao-de-forum-municipal-das-micro-e-pequenasempresas-em-reuniao/> Acesso em: 28 ago. 2017.

PETRY, L. I. ; NASCIMENTO, A. M. Um estudo sobre o modelo de gestão e o processo sucessório em empresas familiares. Revista de Contabilidade e Finanças. São Paulo, v. 20, n. 49, p. 109-125, Abr. 2009. Disponível em: $<$ http://www.scielo.br/scielo.php?script=sci_arttext\&pid=S1519$70772009000100008 \& \operatorname{lng}=e n \& n r m=i s o>$. Acesso em: 31 ago. 2017.

\section{SÁ, A. L. Consultoria e análise contábil. Curitiba: Juruá, 2008.}

SEBRAE. Sobrevivência das Empresas no Brasil. Brasília: SEBRAE, Out. 2016. < http://www.sebrae.com.br/Sebrae/Portal\%20Sebrae/Anexos/sobrevivencia-das-empresas-nobrasil-relatorio-2016.pdf> Acesso em 31 ago. 2017.

. Sondagem conjuntural dos Pequenos Negócios - BR. Jun. 2017a. Disponível em: <https://www.sebrae.com.br/Sebrae/Portal\%20Sebrae/Anexos/7609.pdf> Acesso em: 31 ago. 2017.

Perfil dos Pequenos Negócios. 2017b. Disponível em:

$<$ http://datasebrae.com.br/perfil-dos-pequenos-negocios/> Acesso em: 18 out. 2017.

Santa Catarina: SEBRAE-SC. Critérios de Classificação de Empresas: MEI - ME - EPP. Disponível em: 〈http://www.sebrae-sc.com.br/leis/default.asp?vcdtexto=4154> Acesso em: 18 out. 2017.

SILVA, C. N. Conte comigo! Características da consultoria contábil aos pequenos negócios. 2015. Dissertação (Mestrado em Controladoria e Contabilidade) - Faculdade de Economia, Administração e Contabilidade, Universidade São Paulo, São Paulo, 2015. Disponível em: < http://www.teses.usp.br/teses/disponiveis/12/12136/tde-18012016-161033/en.php> Acesso em: 19 out. 2017.

TRIVIÑOS, A. N. S. Introdução à pesquisa em ciências sociais: a pesquisa qualitativa em educação. São Paulo: Atlas, 1987.

VANNUCCI, I. M. A influência da gestão empresarial na taxa de mortalidade das micro e pequenas empresas de Uberlândia. 2017. 20 f. Trabalho de Conclusão de Curso -

Universidade Federal de Uberlândia, Uberlândia, 2017. Disponível em: < 
http://repositorio.ufu.br/bitstream/123456789/19280/1/InfluenciaGestaoEmpresarial.pdf> Acesso em: 21 nov. 2017.

WILLIAMS, B. R. ; O'DONOVAN, Gary. The accountants' perspective on sustainable business practices in SMEs. Social Responsibility Journal, 2015.

WORLD HEALTH ORGANIZATION Coronavirus disease (COVID-19) pandemic. S.I. 2020. Disponível em: <\&lt;https://www.who.int/emergencies/diseases/novel-coronavirus-

2019? gclid=EAIaIQobChMIl9iHhu3B6wIVxIGRCh2k1gvNEAAYASAAEgJpbfD_BwE\&gt >. Acesso em: 10 jun. 2020.

YASSEEN, Y. An Appreciative Inquiry into the Current and Future Roles of the Professional Accountant in the SME Sector. University of Johannesburg (South Africa), 2019.

Recebido em: 16/04/2020

Aceito em: $\quad 08 / 06 / 2021$ 